\title{
A SHIFT-SHARE ANALYSIS OF JOB CREATION IN THE PLATINUM SDI DURING ITS FIRST DECADE (1996-2006)
}

\author{
Ewert Kleynhans" \\ North West University \\ Ewert.Kleynhans@nwu.ac.za
}

\author{
Carike Claassen+ \\ North West University \\ Carike.Claassen@nwu.ac.za
}

December 2011

\begin{abstract}
This study evaluates the performance of the Platinum Spatial Development Initiative (SDI) development corridor in South Africa, which was initiated during 1996. Next to descriptive data, the study employed shift-share analysis to investigate the economic growth and job creation potential of the manufacturing industries in the SDI region. Analysis of the North West Province was also done to enable comparison with the Platinum SDI. The results revealed that development in the Platinum SDI since 1996 was slightly better than the rest of the province. Sectors with the highest potential were wood and paper products, food and beverages, electronics, furniture and metal products, which merit attention in future development initiatives. Economic growth in the Platinum SDI was, in most cases, better than the rest of the province, and the industrial mix and regional competitive share effects had strong effect on employment and growth in specific sectors.
\end{abstract}

\section{Keywords}

Economic development, economic geography, spatial development initiatives, SDI, industrial development, policy, shift-share analysis, North West Province, South Africa

\footnotetext{
\#Prof Dr Ewert Kleynhans is professor at the School of Economics, North West University, Potchefstroom, South Africa.

+Miss Carike Claassen is a lecturer at the School of Economics, North West University, Potchefstroom, South Africa.
} 


\section{INTRODUCTION}

The Platinum Spatial Development Initiative (SDI) in the North West Province was initiated during 1996, by the Department of Trade and Industry in collaboration with the Department of Transport (DOT, 1997 \& DTI, 1998). The objective was to develop a strip of land about a hundred kilometres wide between Gauteng and Lobatsi in Botswana along the N4 highway. Possible mining, tourism, agricultural and industrial ventures were identified, following expensive research of high-quality and investors' conferences. The idea was to generate linkages with the rest of the province, gradually developing the whole province and eventually the country. This paper aims to evaluate development of the Platinum SDI with special focus on job creation, using shift-share analysis.

In volume 4 issue 1 of the Journal of Economic and Financial Sciences Drewes and Kleynhans (2011) published an evaluation of the achievements of the Platinum SDIs during its first decade of development. They also commented on the five-year evaluation published earlier in Development Southern Africa by Kleynhans, Naudé and Van der Merwe (2003). In 2003 it was concluded that the Platinum SDI lacked a well-defined, operating institutional and bureaucratic framework, and an integrated, well-researched planning process, as well as improved institutional arrangements to coordinate and promote the SDI. It attracted little investment and did not generate much economic growth or employment (Kleynhans et al., 2003:629). Five years on, Drewes and Kleynhans (2011:75) found that the Platinum SDI still did not promote development in the province significantly, and that it could not increase the level of human development of its residents. They concluded that the Platinum SDI was still little more than an "impossible dream". The objective of this paper is to test the validity of this hypothesis.

Drewes and Kleynhans (2011) presented little empirical evidence except for some figures from the Human Development Index (HDI) and value-added production. In the same issue of the Journal of Economic and Financial Sciences Kleynhans and Sekhobela (2011) promoted the use of shift-share analysis as an empirical tool for analysis. This study now intends to employ shiftshare analysis to investigate employment growth in the SDI region and to compare it with the rest of the province.

Shift-share analysis gives insight into the shifts of employment among various regions over time and is easy for policymakers to understand. It shows growth potential and can differentiate between the national share effect of employment in the various sectors of manufacturing, as well as the regional industrial mix and the competitive share effects, providing comparison and much more insight into the various sectors of the region. The article by Kleynhans and Sekhobela (2011) provides a detailed exposition of the literature on shift-share analysis and the various ways it is implemented in practice, and will, therefore, not be repeated here (also see Kleynhans and Sekhobela (2008) for more applications and explanations).

In the articles mentioned above the hypothesis was that the authorities had not succeeded in their attempt to create economic growth and development, using the Platinum Spatial Development Initiative (SDI) as a developmental instrument.

It is the objective of this paper to test this hypothesis empirically. First, the basic methodology will be discussed and an easy way to apply shift-share analysis will be suggested. Then attention will be given to some basic indicators of economic development and finally, the results from the shift-share analysis will be reported on. Here special attention will be given to economic growth, job creation, the effect of national growth, as well as the effect of the particular industrial mix, 
and the effect that the competitive advantage of the various regions have on their ability to create employment and growth.

The following section discusses the research methodology that was used and practical considerations.

\section{THE BASIC METHODOLOGY}

The empirical study was conducted on the various manufacturing industries of the Platinum SDI, as well as those in the rest of the North West Province of South Africa. The research methodology was based on shift-share analysis, which is ideal for studies in economic geography, as in this current study. This study employs a combination of approaches from Bendavid-Val (1993), Armstrong and Taylor (2003), Van der Merwe (2006) and Lann (2005).

The Rex-Database obtained from Global Insight (2012) was used because it provided the relevant data broken down to municipal and magisterial level. The database provides not only national data for indicators, like employment and gross value added, but also detail on provincial and town, including a breakdown of the various sub-divisions of manufacturing, for example, basic metals, food and beverages, and electrical machinery.

To obtain the specific data for the Platinum Spatial Development Initiative (SDI) and the North West Province excluding the SDI region, the data from the various municipalities (managerial districts) was summarised. Table 1 shows the division between the magisterial districts located within the Platinum SDI and those located in the rest of the North West Province, according to the 1996 boundaries. Strictly speaking Mmabatho is not part of the Platinum SDI any longer, but the N4 highway passes through part of the district and the border post Ramatlabama to Lobatsi in Botswana is located at the western border of Mmabatho. Excluding Mmabatho would also bias the study in favour of its hypothesis.

TABLE 1: Magisterial districts of the Platinum SDI and the rest of North West Province (1996 boundaries)

\begin{tabular}{lc}
\hline Rest of North West & Platinum SDI \\
\hline Huhudi & Mmabatho \\
Kudumane & Madikwe \\
Vryburg & Rustenburg \\
Phokwani & Brits \\
Lichtenburg & \\
Delareyville & \\
Schweizer-Renecke & \\
Wolmaransstad & \\
Christiana & \\
Klerksdorp & \\
Ventersdorp & \\
Potchefstroom & \\
Mankwe & \\
Ga Rankuwa & \\
Temba &
\end{tabular}

Source: Global Insight,2012-Rex Database 
The research period from 1996 to 2006 reflects the development in the region during the first decade of initiation. To allow comparison of growth in this static model, the research period was divided into two periods: comparing the development of the period 1996 to 2001 with that of 2002 to 2006. This is actually eleven years but 1996 was not a full year because the Platinum SDI was established during 1996. The time period chosen also excluded the economic crisis of the later part of the decade, which could complicate matters.

Employment opportunities in the various sub-sectors of the manufacturing industry in the region were disaggregated into three components: the national share effect $(\mathrm{N})$, industry mix effect $(M)$ and the regional competitive share effect $(S)$. The sum of these three components gives the total change in regional employment (R) (Mayor \& López, 2008:125),

$$
\text { thus } \mathbf{R}=\mathbf{N}+\mathbf{M}+\mathbf{S}
$$

The total size of employment created or lost in the region, as a net effect of national growth, the industry mix and regional characteristics, is represented by the variable $\mathrm{R}$. The potential growth of the region is represented by $\mathrm{N}$, assuming that employment in the region is growing at the same rate as the national average, while $M$ is the proportion of regional employment among faster and slower growing regional sectors relative to the national average growth rate, while $S$ describes how sectors in the region perform relative to the national averages of the same sectors (Kleynhans \& Sekhobela, 2008, 2011).

The change in provincia/employment of North West Province is the difference:

$$
\mathbf{E}(\mathbf{v})=\mathbf{E}_{\mathrm{tf}}-\mathbf{E}_{\mathrm{to}}
$$

where $\varepsilon(v)$ is the change in employment, $\varepsilon_{\mathrm{tf}}$ is the total gross value added in the final period and $\varepsilon_{\text {to }}$ is total employment in the initial period. The national average employment growth rate $\varepsilon(\%)$ is defined as:

$$
E(\%)=\left[E_{t f} / E_{t o}-1\right] \times 100
$$

The total change in regiona/ employment $(R)$ is the difference in total employment in the final period and the initial period and is calculated as:

$$
\mathbf{R}=\mathbf{e}_{\text {tf }}-\mathbf{e}_{\text {to }}
$$

where $\mathrm{R}$ is the total change in regional employment, e is the total employment in the region, "to" is the initial period, "tf" is the final period of analysis.

Total percentage change in regional employment $R(\%)$ is the total final regional employment divided by the total initial regional employment minus one, multiplied by 100 , which implies a growth rate and is calculated as follows:

$$
R(\%)=\left[e_{t f} / e_{t o}-1\right] \times 100
$$

The National Share $\varepsilon f f e c t ~(N)$ is an indicator of possible regional employment growth, if each of its sectors and, therefore, the regional total grew at the same rate, as the national employment growth average. The National Share effect $(\mathrm{N})$ is determined by:

$$
\mathbf{N}=\sum_{k=1}^{n} \mathbf{e}_{\text {tok }}(\mathbf{E} \%)
$$


where $\mathrm{N}$ is the total national share of the manufacturing industry, $\mathrm{e}$ is the regional employment in sectors $1,2 \ldots$ up to $n$ in the initial period $t_{0}$ and $\varepsilon \%$ is the national employment growth rate (see equation 3).

The industrial mix component gives an indication of how the region's industrial structure factors fit into its overall employment growth performance (Nazara \& Hewings, 2004:476). When local employment is concentrated in the fast growing sectors, the rate of local employment growth would exceed the national average. If regional employment is concentrated in slow growing sectors, the growth rate of regional employment would be lower than the national economywide average. The change in employment due to the region's unique industry mix is therefore represented by the Industry Mix $\varepsilon f f e c t(M)$, which is defined by the equation:

$$
\mathbf{M}=\sum_{k=1}^{n} \mathbf{M R}_{\mathbf{k}}\left(\mathbf{e}_{\text {tok }}\right)
$$

where MR is the marginal rate of growth in sectors $1,2,3, \ldots$ up to $n$ and $e_{\text {to }}$ is region's sectoral employment in the initial year.

The Regional Competitive Share Effect (S) represents how sectors in the region performed relative to the national averages of the same sectors. From equation (1) the total change in regional gross value added is defined as:

$$
\mathbf{S}=\mathbf{R}-\mathbf{N}-\mathbf{M}
$$

The next section will consider the basic development indicators, followed by the estimation of $\mathrm{N}$, $M, S$ and R using equations 1 to 8 above. TABLE 3 gives an overview of the whole process for the Platinum SDI for the entire research period.

\section{BASIC DEVELOPMENT INDICATORS}

This section will consider the basic development indicators of the Platinum SDI in comparison with the section of the North West Province that is not located in the Platinum SDI. Attention will be given to the HDI, the Gini coefficient and the urbanisation rate.

\subsection{Human Development Index (HDI)}

The Human Development Index (HDI) of the Platinum SDI has increased marginally since 1996, from 0.51 to 0.56 , where 1 represents total development. It also lies above the rest of the North West Province. The SDI was, however, higher from the start (Drewes \& Kleynhans, 2011:74). Annual averages were calculated, grouping the magisterial districts between those located in the Platinum SDI and those located in the rest of the province's districts, excluding the SDI. During the ten years under investigation the HDI in the whole North West Province was between 0.37 and 0.62 .

The HDI is a composite measure of development using health, education and income as components. South Africa had a HDI of 0.653 during 2004 and North West Province 0.54 (REX database). In the same year Norway was 0.965 , USA 0.948 , Angola 0.44 and Ethiopia 0.37 (UNDP, Human Development Report 2006:283-6). 
Pearson coefficients of correlations were estimated to determine how much the data of the various regions varies over time (Keller, 2001:568). There is not enough data to conduct regression analysis, but it was not perceived to be necessary at this stage. When the coefficient of correlation was calculated for the Platinum SDI, it equalled 0.995, which implied that there was no significant difference between the development (HDI) of the Platinum SDI and the rest of the province. The correlation matrix indicated a correlation between these two regions, so close that these data series were virtually identical.

\subsection{Measure of income distribution: The Gini coefficient}

The Gini coefficient is a measurement of income distribution, where a Gini coefficient equal to zero indicates perfectly equality. It was found that income distribution in the Platinum SDI had improved and was much better than the rest of the province. Figure $\mathbf{l}$ indicates that the rest of the province has actually deteriorated since 1999.

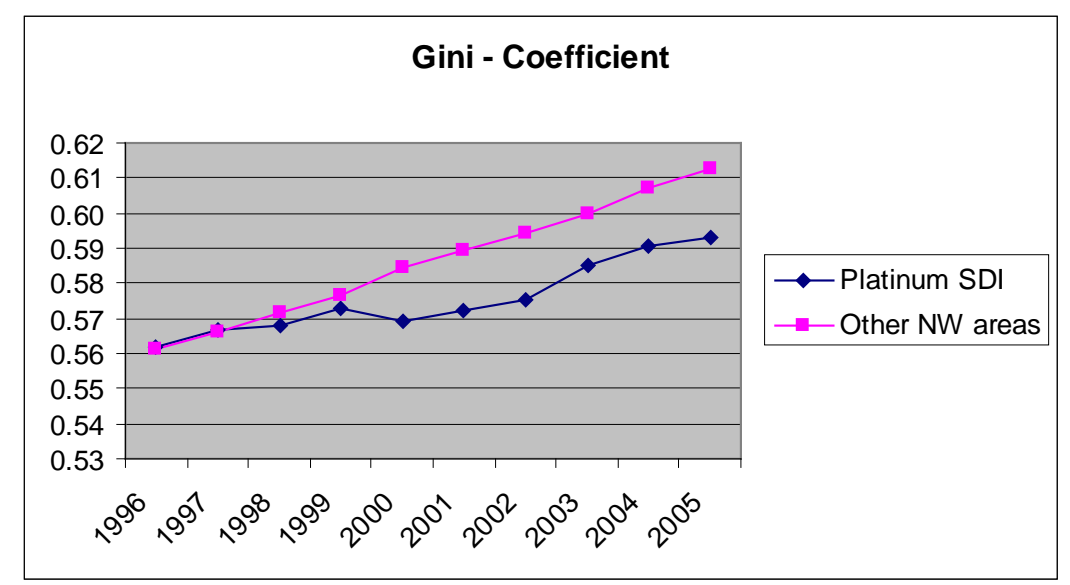

FIGURE 1: Gini coefficient

Source: Rex Database, 2012 - Authors' calculations

The Pearson coefficient of 0.941 indicated a very close correlation and no significant difference.

\subsection{Urbanisation rate}

The urbanisation rate represents the percentage of people living in urban areas, where $100 \%$ implies that everybody in the region or district is located in the urban area. During 2004 South Africa had an urbanisation rate of $56.2 \%$ and North West Province $40.1 \%$ (REX database). In the same year Norway was $77.3 \%$ urbanised, USA $80.5 \%$, Angola $52.7 \%$ and Ethiopia $15.7 \%$ (UNDP, Human Development Report, 2006:297-300). On average it seems as if the richer countries have higher urbanisation rates.

It was found that the districts lying along the Platinum SDI were far less urbanised than the rest of the province. This is due to the high level of development along the N12 route, as well as in Vryburg (90.5\%) and Schweizer-Renecke (86.9\%), which is not located in the SDI. The high urbanisation rates along the N12 highway are probably due to the amount of traffic between Johannesburg and the historically diamond-rich city of Kimberley. 
Similar to the Human Development Indices, there were remarkable differences in urbanisation rates of those districts located along the Platinum DSI and those in the rest of the province. However, when correlations were determined, it was found that the correlation coefficients indicate such large correlations that the trends in the data series were virtually identical, and no significant differences existed. The coefficient of correlation between the Platinum SDI and magisterial districts in the rest of the province equals 0.915 , indicating a very strong correlation (Rowntree, 1991:170).

The following section reports some of the findings of the shift-share analysis done on the Platinum SDI.

\section{EMPIRICAL RESULTS}

This section reports on the research results from the shift-share analysis.

\subsection{Shift-Share results of the Platinum SDI}

The results of the shift-share analysis done on the Platinum SDI for the period 1996 to 2006 are given in TABLE 3. FIGURE 2 shows the growth in employment of the Platinum SDI's industries between 1996 and 2006. It can be seen that the sectors for metal products, wood and paper products, food and beverages created most jobs.

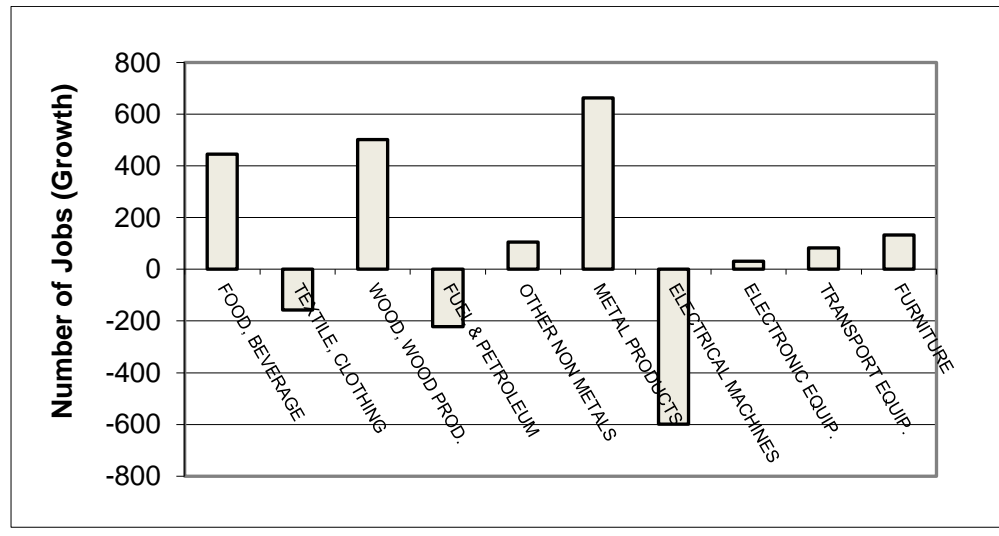

FIGURE 2: Employment growth in the Platinum SDI

Source: Rex Database, 2011 - Authors' analysis

If the Platinum SDI region had grown at the same rate as the country, all the sectors would be worse off, due to the national share effect - see FIGURE 3. 


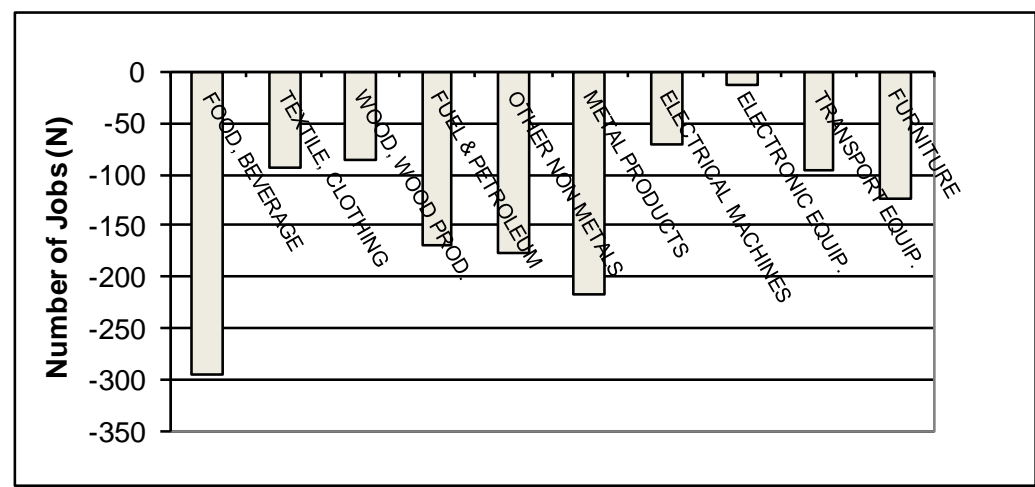

FIGURE 3: Platinum SDI: National Share \&ffect (N)

Source: Rex Database, 2011 -Authors' analysis

Considering the job creation due to the industrial mix in the Platinum SDI region, FIGURE 4 indicates that the region gained some jobs due to the region's particular industrial mix. Metal products, wood and paper products, transport equipment and the furniture sectors gained many employment opportunities, but the rest all lost employment due to the industrial mix effect. Only the four growing sectors mentioned experienced employment growth higher than the provincial average.

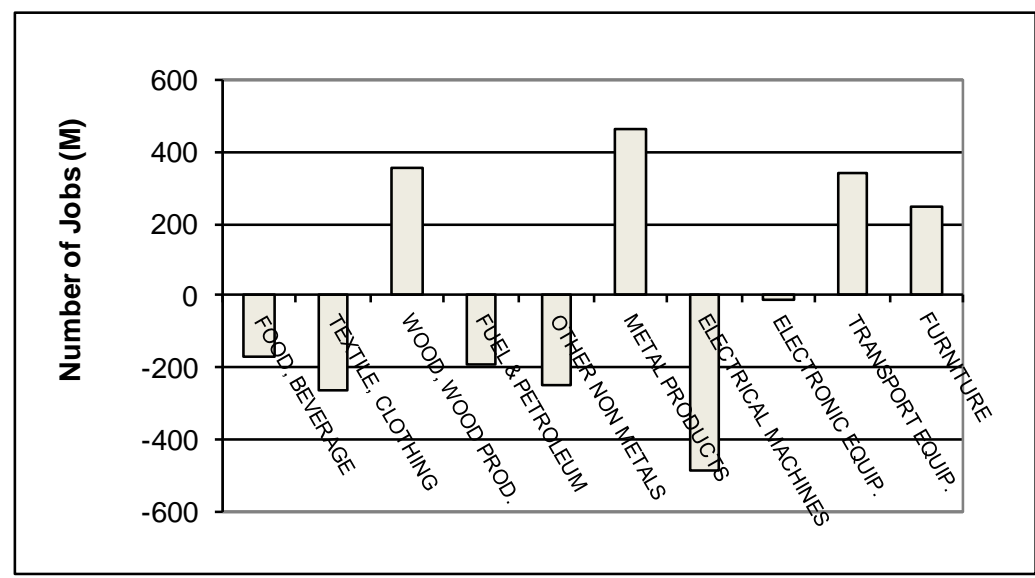

FIGURE 4: Platinum SDI: The Industrial Mix Effect (M)

Source: Rex Database, 2011 -Authors' analysis

According to FIGURE 5 there was a very large shift in employment opportunities towards the Platinum SDI region due to the region's excellent regional competitive share effect. The employment gain due to this effect was $11.4 \%$. FIGURE $\mathbf{5}$ indicates that the sectors that gained most in this regard were the sectors for food and beverages, metal products and other nonmetal mineral products. 


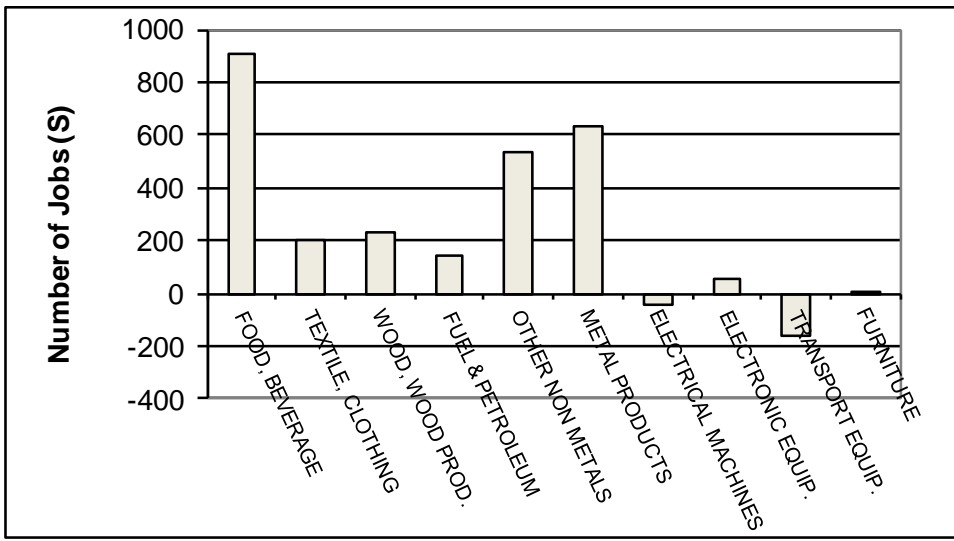

FIGURE 5: Platinum SDI: Regional Competitive Share Effect (S)

Source: Rex Database, 2011 -Authors' analysis

Considering the Platinum SDI in total, the results revealed that development in the Platinum SDI since 1996 was excellent and had created many employment opportunities. Sectors with the highest potential were wood and paper products, food and beverages, electronics, furniture and metal products, and they merit attention in future development initiatives. The following section considers the shift-share effects and growth rates of the Platinum SDI in comparison with the rest of the North West Province.

\subsection{Growth in employment}

Comparing average growth rates of the various regions (see TABLE 2) for the whole period under investigation (1996-2006), the Platinum SDI grew 5\%, while the North West Province declined by $7 \%$ and the province excluding the Platinum SDI (called "the Rest" from here on) declined by negative $14 \%$. Employment grew strongly in the SDI, $19 \%$ better than the rest of the province and $12 \%$ better than the provincial average.

In the initial six years (1996-2001) employment opportunities declined by 5\%, while the provincial average dropped by $16 \%$ and the rest of the province diminished by a staggering $22 \%$. This implies a decline in employment, but not as bad as the regions outside of the Platinum SDI. The province lost $11 \%$ more jobs than the SDI, while those areas outside the SDI lost $17 \%$ more. It seems as if the Platinum SDI has done much better than the rest.

During the period 2002 till 2006 many job opportunities were gained. The average employment in the North West Province grew by $8 \%$, the rest of the province by $9 \%$ and the Platinum SDI by only $6 \%$. Employment in the SDI grew well, but provincial growth was $2 \%$ better and those areas outside the SDI surpassed it by $3 \%$. In this period there was economic prosperity in the whole of South Africa and also in North West Province. 
TABLE 2: Comparison of growth rates

\begin{tabular}{l|ccc|ccc|ccc}
\hline \multicolumn{1}{c|}{ GrowthRates } & $196-$ & $96-$ & $196-$ & $96-$ & $96-$ & $96-$ & $02-$ & $02-$ & $02-$ \\
\multicolumn{1}{c}{ SECTOR } & NW & 06 & 06 & 01 & 01 & 01 & 06 & 06 & 06 \\
\hline FOOD, BEVERAGE & -11 & 11 & -25 & -10 & 11 & -24 & -1 & -2 & 0 \\
TEXTILE, CLOTHING & -27 & -12 & -31 & -17 & 1 & -22 & -14 & -16 & -13 \\
WOOD, WOOD PROD. & 22 & 41 & 11 & 10 & 27 & 0 & 8 & 6 & 9 \\
FUEL \& PETROLEUM & -15 & -9 & -20 & -6 & 0 & -11 & -12 & -13 & -12 \\
OTHER NON METALS & -17 & 4 & -29 & -40 & -25 & -48 & 38 & 37 & 38 \\
METAL PRODUCTS & 8 & 21 & -1 & -18 & -8 & -24 & 26 & 24 & 27 \\
ELECTRICAL & -55 & -59 & -49 & -23 & -31 & -11 & -42 & -42 & -43 \\
MACHINES & -16 & 18 & -31 & -15 & 18 & -30 & 4 & 3 & 5 \\
ELECTRONIC EPUIP. & 18 & 6 & 28 & -19 & -27 & -12 & 45 & 45 & 46 \\
TRANSPORT EPUIP. & 7 & 7 & 6 & -13 & -13 & -14 & 13 & 11 & 15 \\
FURNITURE & & & & & & & & & \\
\hline
\end{tabular}

Source: Global Insight, 2012-Rex Database-Authors' calculations

The idea that the government supported the SDIs well during the initial period but lost interest along the way seems to be substantiated. It is, however, difficult to isolate the results of the SDI initiatives from other factors.

Comparing the two research periods revealed that the Platinum SDI has grown by $10 \%$, while jobs in the North West Province as a whole grew by $24 \%$ and the change in the rest of the province, excluding the SDI, grew by $31 \%$, from negative 22 to positive 7 . This again implies that the SDI actually grew less than the rest of the province.

\subsection{The National Share Effect (N)}

The national share effect indicates how much regional employment would have grown, had each of its sectors and, therefore, the total region, grown at the same rate as the national average employment growth. TABLE 3 presents the results for the Platinum SDI between 1996 and 2006.

During the period 1996 to 2001 employment growth was even worse, causing a decline of $17 \%$ in the Platinum SDI and a decline of $21 \%$ in the rest of the province. There was positive growth in the next five years though, where jobs in the SDI grew by $8 \%$ and the rest of the province by $7 \%$. In this period (2001-2006) the effect of the Competitive Share and Industrial Mix turned negative in the SDI, though the Competitive Share became very strong in the rest of the province, outside the SDI. 
Kleynhans \& Claassen

TABLE 3: Shift-Share analysis of the Platinum SDI (1996-2006)

\begin{tabular}{lcccccc}
\hline \multicolumn{1}{c}{ SECTOR } & 1996 & 2006 & $R$ & $N$ & $M$ & $S$ \\
\hline FOOD, BEVERAGE & 4238 & 4683 & 445 & -297 & -170 & 912 \\
TEXTILE, CLOTHING & 1325 & 1167 & -158 & -93 & -265 & 200 \\
WOOD, WOOD PROD. & 1235 & 1737 & 502 & -86 & 358 & 230 \\
FUEL \& PETROLEUM & 2416 & 2194 & -222 & -169 & -193 & 140 \\
OTHER NON METALS & 2510 & 2615 & 105 & -176 & -251 & 532 \\
METAL PRODUCTS & 3104 & 3768 & 664 & -435 & 466 & 633 \\
ELECTRICAL MACHINES & 1015 & 416 & -599 & -71 & -487 & -41 \\
ELECTRONIC EPUIP. & 169 & 200 & 31 & -12 & -15 & 58 \\
TRANSPORT EQUIP. & 1371 & 1454 & 83 & -96 & 343 & -164 \\
FURNITURE & 1785 & 1918 & 133 & -125 & 250 & 8 \\
TOTAL & 19168 & 20152 & 984 & -1342 & 36 & 2290 \\
\hline
\end{tabular}

Source: Global Insight, 2012-Rex Database-Authors' calculations

\subsection{The industrial mix effect (M)}

The advantage that a region gains due to its particular mix of industries also has an influence on employment growth and this aided employment growth during the research periods. The industry mix component shows how the region's industrial structure factors affected its overall employment growth performance (Kleynhans \& Sekhobela, 2011:20).

The rate of local employment growth would exceed the national average when local employment is concentrated in the fast growing sectors. On the other hand, the growth rate of regional employment would be lower than the national economy-wide average if the regional employment is concentrated in slow growing sectors. The industry mix effect is calculated as a product of the region's sectoral employment in the initial year and the marginal rate of growth. The marginal rate of growth (MR) is the difference between the national sectoral growth and the national average growth.

TABLE 4 shows the contribution that the industrial mix effect had, relative to the size of a sector in a specific region. It can be seen that the total effects were very limited, but the industrial mix effects were rather strong in specific sectors, like wood and paper products, metal products, and transport equipment. In the sectors for textiles, chemicals and petroleum, and electrical machinery, it was very negative. There was also not much difference between the industrial mix effects of the various sectors in the Platinum SDI and that of the rest of the province. 
TABLE 4: Industrial mix, percentage contribution

\begin{tabular}{|c|c|c|c|c|c|c|c|}
\hline $\begin{array}{r}\text { (M\%) } \\
\text { SIC }\end{array}$ & SECTOR & $\begin{array}{c}96-06 \\
S D I\end{array}$ & $\begin{array}{c}196-06 \\
\text { Rest }\end{array}$ & $\begin{array}{c}96-01 \\
S D I\end{array}$ & $\begin{array}{l}96-01 \\
\text { Rest }\end{array}$ & $\begin{array}{c}02-06 \\
S D I\end{array}$ & $\begin{array}{l}02-06 \\
\text { Rest }\end{array}$ \\
\hline 30 & FOOD, BEVERAGE & -3.6 & -5.4 & 5.4 & 7.4 & -9.2 & -9.0 \\
\hline 31 & TEXTILE, CLOTHING & -22.7 & -28.9 & -1.0 & -0.7 & -26.6 & -25.7 \\
\hline 32 & WOOD, WOOD PROD. & 20.6 & 26.1 & 20.5 & 26.0 & -0.4 & -0.4 \\
\hline 33 & FUEL \& PETROLEUM & -8.8 & -10.0 & 10.0 & 11.1 & -23.3 & -22.9 \\
\hline 34 & OTHER NON METALS & -9.6 & -14.1 & -32.2 & -46.2 & 21.7 & 21.5 \\
\hline 35 & METAL PRODUCTS & 12.4 & 15.1 & -2.2 & -3.0 & 14.5 & 14.2 \\
\hline 36 & ELECTRICAL MACHINES & -117.1 & -94.1 & -10.1 & -7.8 & -87.1 & -87.7 \\
\hline 37 & ELECTRONIC EQUIP. & -7.5 & -13.2 & 0.8 & 1.0 & -4.3 & -4.2 \\
\hline 38 & TRANSPORT EQUIP. & 23.6 & 19.6 & -4.1 & -3.0 & 25.8 & 25.6 \\
\hline 39 & FURNITURE & 13.0 & 13.2 & 3.4 & 2.9 & 4.3 & 4.1 \\
\hline Total & TOTAL & 0.18 & 0.49 & 0.45 & 0.25 & -0.29 & -0.19 \\
\hline
\end{tabular}

Source: Global Insight, 2012-Rex Database-Authors' calculations

\subsection{Regional competitive share effect (S)}

The regional competitive share effect describes how sectors in a region perform relative to the national averages of the same sectors. This is calculated by multiplying the base year employment in each regional sector with the margin between the regional sector's growth rate and the national average growth rate of that sector (Kleynhans \& Sekhobela, 2008:18). This is simply the difference between $\mathrm{R}, \mathrm{N}$ and $\mathrm{M}$. If the region increased its share of employment in that industry, the regional competitive share effect would be positive, while a negative competitive share component suggests that the region's employment share eroded during the period under investigation.

TABLE $\mathbf{5}$ compares the number of jobs that was created due to the specific region's regional competitive share effect $(S)$. It can be seen that the SDI gained about as many jobs as those lost in the rest of the province, in each case. Percentage contribution relative to the size of the various sectors seems to be in favour of the SDI, which experienced overall growth of $11 \%$, while the rest of the province lost $8 \%$ jobs due to their relative uncompetitiveness. It seems as if the initiatives of the Platinum SDI had some positive influence, but during the period 2002 to 2006, when the whole country enjoyed high positive economic growth, the Platinum SDI lost 231 jobs, while the rest of the province outside the Platinum SDI gained 300 jobs. This was, however, much smaller when expressed in percentages where the SDI lost only $1.2 \%$ compared with its $11 \%$ earlier growth, while the rest of the province only gained $1.05 \%$ employment. 
Kleynhans \& Claassen

TABLE 5: Regional competitive share effect (s)

\begin{tabular}{l|cc|cc|cc}
\hline \multicolumn{1}{c|}{ Jobs } & $96-06$ & $196-06$ & $96-01$ & $96-01$ & $02-06$ & $02-06$ \\
& SDI & Rest & SDI & Rest & SDI & Rest \\
\hline FOOD, BEVERAGE & 912 & -946 & 896 & -914 & -55 & 55 \\
TEXTILE, CLOTHING & 200 & -177 & 237 & -232 & -30 & 30 \\
WO0D, WOOD PROD. & 230 & -234 & 212 & -212 & -30 & 29 \\
FUEL \& PETROLEUM & 140 & -159 & 147 & -148 & -17 & 17 \\
OTHER NON METALS & 532 & -541 & 367 & -366 & -14 & 15 \\
METAL PRODUCTS & 633 & -445 & 301 & -308 & -49 & 49 \\
ELECTRICAL MACHINES & -41 & 40 & -77 & 76 & 1 & -1 \\
ELECTRONIC EPUIP. & 58 & -59 & 56 & -57 & -1 & 3 \\
TRANSPORT EQUIP. & -164 & 171 & -116 & 120 & -6 & 5 \\
FURNITURE & 8 & -32 & 3 & -11 & -31 & 98 \\
TOTAL & 2290 & -2383 & 2027 & -2051 & -231 & 300 \\
\hline Total Percentage Share \% & 11.36 & -8.36 & 11.13 & -7.95 & -1.15 & 1.05 \\
\hline
\end{tabular}

Source: Global Insight, 2012-Rex Database-Authors' calculations

\section{SUMMARY AND CONCLUSION}

It was the objective of this study to assess the ability of the Platinum SDI to create employment and compare it with the rest of the North West Province during the period 1996 to 2006 . The initial hypothesis was that the initiatives of the Platinum SDI did not make any difference to the province's ability to create employment, and neither did it advance any economic development. This study could not fully substantiate this hypothesis and had to reject it. The authors wished to show that the initiatives of the Platinum SDI had no positive results. The empirical results, however, revealed that there were significant positive outcomes and that growth and development in the Platinum SDI were in fact greater than the rest of the North West Province.

The objective of this article was to empirically test the results of a previous evaluation of the Platinum SDI, published during 2011 in the Journal of Economic and Financial Sciences. The article commenced with an explanation of an easy method to analyse employment growth on local municipal level using very little data, as this is usually an obstacle to these types of spatial research. Shift-share analysis was then applied to the region under investigation.

The study found that economic growth was, in most cases, better in the Platinum SDI region than in the rest of North West Province. The industrial mix had a strong effect in specific sectors, but then the difference between the SDI and the rest was not significant. Difference in other economic development indicators, like the Human Development Index (HDI), the Gini coefficient and urbanisation rate, was also not significant. The creation of employment due to the regional competitive share effects was also stronger in the SDI Region. The SDI experienced some negative growth in this regard during the last period, but compared with the previous years, it was insignificant. In total the results revealed that development in the Platinum SDI since 1996 has been slightly better than the rest of the province. Sectors with the highest potential were 
wood and paper products, food and beverages, electronics, furniture and metal products, and they merit attention in future development initiatives.

The shift-share analysis methodology presents a unique opportunity to compare even small regions and analyse the various components of employment growth in detail, but the problem is still that the influence of initiatives of the Platinum SDI cannot be isolated from other influences. Mmabatho, Rustenburg and Brits were strong economic centres even before the instigation of the Platinum SDI. This was probably part of the motivation to locate the SDI there in the first place. The rest of the province experienced several goldmines closing down as they become redundant, while several new platinum mines are currently expanding near Rustenburg and Brits. Shift-share analysis is a good first step in analysing the research problem, but further research is still necessary.

This paper also did not give adequate attention to the results obtained from the shift-share analysis. The various sectors now have to be analysed individually to determine the kind of growth in each sector, especially in sectors where comparative advantage existed historically. The study should be extended to include mining and services because these are very important sectors in the province, with several goldmines closing down and large platinum reserves being recently discovered and numerous mining operations commencing. The results obtained in this study also indicate which sectors have the potential for further growth and job creation. The strong competitive share and growth potential of transport equipment, non-metal as well as metal products and furniture sectors were significant, and merit further attention in future.

\section{LIST OF REFERENCES}

Armstrong, H. \& Taylor, J. (2003). Regional Economics and Policy. New York: Harvester.

Bendavid-Val, A. (1993). Regional and Local Economic Analysis for Practitioners. New York: Prager.

Department of Trade and Industry (DoT). (1998). Industrial policy and programmes in South Africa. Discussion document. Compiled by the Industrial Development Corporation for the DTI. Publisher?

Department of Transport (DTI). (1997). Annual Report 1996-1997. Pretoria: DoT.

Drewes, દ. \& Kleynhans, દ.P.J. (2011). Evaluation of the Platinum SDI: A Critical Commentary. Journal of Economic and Financial Sciences, 4(1), pp. 63-80.

Global Insight (Southern Africa). (2012). Rex-Database. [Online] Available:

http://www.globalinsight.co.za. (Accessed 17 April 2012).

Keller, G. (2001). Applied Statistics with Microsoft Excel. Pacific Grove: Duxbury/Thomson.

Kleynhans, E.P.J., Naudé, W.A. \& Van der Merwe, S.J. (2003). Spatial Economic Development in South Africa: An Overview and Evaluation of the Platinum Spatial Development Initiative. Development Southern Africa, 20(5), pp. 617-631.

Kleynhans, દ.P.J. \& Sekhobela, M.J. (2011). Shift-Share Analysis of Production in the Manufacturing Industry of South Africa's Southern District Municipality. Journal of Economic and Financial Sciences, 4(1), pp. 10-30.

Kleynhans, E.P.J. \& Sekhobela, M.J. (2008). Shift-Share Analysis of Manufacturing as a Measuring Instrument for Human Resource Management. South African Journal of Human Resource Management, 6(3), pp. 14-21. 
Lann, R. (2005). Shift-Share Analysis: Mix and Share Analysis. Georgia: Economic Development Institute. Georgia Institute of Technology (Georgia Tech). [Online] Available:

http://www.cherry.gatech.edu/6602/PRESENT/shift-share\%20analysis.ppt\#6. (Accessed 07 August 2007).

Mayor, M. \& López, A.J. (2008). Spatial Shift-Share Analysis versus Spatial Filtering: An Application to Spanish Employment Data. Empirical Economics, 34, pp. 123-142.

Nazara, S. \& Hewings, G.J.D. (2004). Spatial Structure and Taxonomy of Decomposition in Shift-Share Analysis. Growth and Change, 35(4), pp. 476-490.

Rowntree, D. (1991). Statistics without Tears. London: Penguin.

Rex-Database see Global Insight.

UNDP. (2006). Human Development Report. New York: United Nations Development Programme.

Van Der Merwe, J. (2006). Shift-Share Analysis: An Alternative Study of Regional Growth with Panel Data. Unpublished BCom Hons mini-dissertation. Potchefstroom: North-West University. 